\title{
In Vitro Efficacy of Four Insecticides Against Eggs of Tunga penetrans (Siphonaptera)
}

\author{
Tim Kiesewetter ${ }^{1}$, Liana Ariza ${ }^{2}$, Maria M. Martins ${ }^{3}$, Jean E. Limongi ${ }^{4,5}$, Juliana Junqueira da Silva ${ }^{5}$, \\ Júlio Mendes ${ }^{4}$, Cláudia M. Lins Calheiros ${ }^{6}$, Heiko Becher ${ }^{7}$ and Jorg Heukelbach ${ }^{*, 2,8}$ \\ ${ }^{1}$ School of Medicine, University of Cologne, Cologne, Germany \\ ${ }^{2}$ Department of Community Health, School of Medicine, Federal University of Ceará, Fortaleza, Brazil \\ ${ }^{3}$ Faculty of Veterinary Medicine, Federal Universidade of Uberlândia, Uberlândia, Brazil \\ ${ }^{4}$ Institute of Biomedical Sciences, Federal Universidade of Uberlândia, Uberlândia, Brazil \\ ${ }^{5}$ Centre of Control of Zoonotic Diseases, Municipal Health Secretariat of Uberlândia, Minas Gerais, Brazil \\ ${ }^{6}$ Institute of Biological Sciences and Health, Federal University of Alagoas, Maceió, Brazil \\ ${ }^{7}$ Institute of Public Health, University of Heidelberg, Heidelberg, Germany \\ ${ }^{8}$ Anton Breinl Centre for Public Health and Tropical Medicine, School of Public Health, Tropical Medicine and \\ Rehabilitation Sciences, James Cook University, Townsville, Australia
}

\begin{abstract}
Systematic assessments of control measures against the jigger flea Tunga penetrans are scarce, and there are no published data available on the efficacy of environmental insecticides against immature stages. We tested four environmental contact insecticides used by Brazilian authorities for disease control (deltamethrin, bifenthrin, dichlorvos and etofenprox) against $T$. penetrans eggs. Eggs were reared in vitro. Hatch rates were observed under standardized conditions and compared to a control group (40 eggs in each group). No larvae hatched after treatment with the organophosphate dichlorvos (100\% efficacy). The efficacies of the other products tested varied between $17 \%$ and $57 \%$. The data show that the organophosphate dichlorvos had a good in vitro efficacy. The use of dichlorvos can be directed to typical spots where early stages of $T$. penetrans are expected, considering its toxicity. Disease control should also consist of prevention measures concerning housing and environmental conditions, veterinary and human health measures.
\end{abstract}

Keywords: chigoe flea, efficacy, insecticides, prevention, Tunga penetrans.

\section{INTRODUCTION}

Infestation with the jigger flea Tunga penetrans (tungiasis) is a Neglected Tropical Disease causing substantial health burden in endemic areas [1]. Though affecting many people in resource-poor communities in subSaharan Africa, the Caribbean and Latin America, systematic evaluations of control measures against tungiasis are scarce [2-4].

Control of tungiasis is complex and would need an interdisciplinary approach [5]. The prevalence in humans in endemic regions can easily reach more than $50 \%$ and cause considerable morbidity [6-12]. Domestic animals such as pigs and dogs are the main animal reservoirs, and control measures thus would need to consider domestic animals [4, $5,13]$. In addition, immature stages are found in the environment where they may survive for a prolonged period

*Address correspondence to this author at the Departamento de Saúde Comunitária, Faculdade de Medicina, Universidade Federal do Ceará, Rua Professor Costa Mendes 1608, 5. andar, Fortaleza CE, 60430-140, Brazil; Tel: ++55-85-33668045; Fax: ++55-85-33668050;

E-mail: heukelbach@web.de
[14]. For emergency control measures, eggs may be treated with environmental insecticides, but there are no efficacy data available on these insecticides against immature stages of T. penetrans. For example, in Rio Grande do Sul State in the extreme south of Brazil, the State Health Secretariat regularly sprays compounds of affected houses with alphacypermethrin without any evidence.

To provide evidence for control measures, we tested four insecticides used in disease control programs in Brazil against $T$. penetrans eggs. Eggs were reared in vitro, and hatch rates were observed under standardized conditions.

\section{MATERIALS AND METHODS}

The study was carried out in the city of Uberlândia (Minas Gerais State), situated in Brazil's savannah region. To obtain fertile $T$. penetrans eggs, laboratory-raised Wistar rats were exposed according to procedures described previously on compounds in the outskirts of Uberlândia where tungiasis occurs [15-17].

From September to October 2010, a total of 25 rats were exposed at 11 different locations. Two in two days, the infestation status and general status of animals were 
assessed. The rats were transported after 5 to 7 days to the laboratory of the Federal University of Uberlândia for a thorough examination. The lesions were counted and classified according to the Fortaleza Classification [18]. Infested rats with the embedded fleas expelling eggs (stage 3 according to Fortaleza Classification; Fig. 1) were held over black cardboard for 3 to 5 hours to facilitate detection and collection of deposited eggs. Eggs were examined for physical integrity, counted and transferred to Petri dishes.

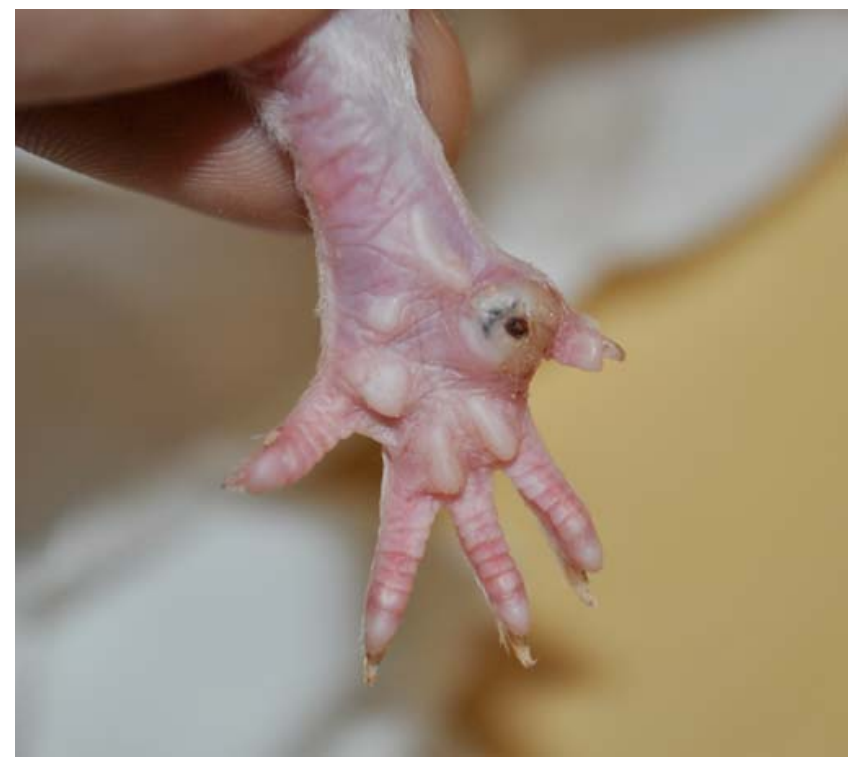

Fig. (1). Rat infested with $T$. penetrans (stage III according to Fortaleza Classification).

Environmental insecticides tested are given in Table $\mathbf{1 .}$ All insecticides are registered by the Brazilian Ministry of Health for peridomestic and environmental spraying. The concentration was chosen as recommended in the product information for the control of small insects (Table 1). These concentrations are also used by the centers for zoonosis control throughout Brazil. In each insecticide and control group, 40 eggs were tested. Batches of eggs were pooled and then randomized into one of the four treatment or control groups. $175 \mu \mathrm{l}$ of the insecticide were applied from $5 \mathrm{~cm}$ distance using a standardized hand pump spray bottle. That equals an application of about $0.0221 / \mathrm{m}^{2}$. In the control group tap water was used.

The Petri dishes were placed in a polystyrene box and incubated at environmental temperature $\left(24.7-27.8^{\circ} \mathrm{C}\right)$. To establish consistent humidity, damp cloth was placed inside the boxes. Relative humidity varied from $50.4 \%$ to $71 \%$. After 3, 5 and 7 days the eggs were examined for hatching, and larvae counted. All procedures and examinations were conducted by a single observer to prevent inter-observer variation.

Data were entered using Excel spread sheets and checked for entry errors. Corrected hatch rates were calculated as: (crude hatch rate in test group) / (crude hatch rate in untreated control group). Efficacy of a product was defined as: (1 - corrected hatch rate). Negative values (hatch rate in intervention group higher than in control group) were considered as $0 \%$ efficacy. $95 \%$ confidence intervals for efficacy were calculated according to an asymptotic formula, as described by Rosenheim and Hoy [19]. Calculated values below $0 \%$ or above $100 \%$ in confidence intervals were set to $0 \%$ or $100 \%$, respectively. Relative frequencies between groups were compared applying Fisher's exact test to evaluate statistical significance. Analysis was done using SAS (version 9.2, SAS Institute Inc., Cary, USA).

The study was approved by the Ethical Review Board for Animals (Comissão de Ética na Utilização de Animais $C E U A$ ) of the Universidade Federal de Uberlândia, protocol no. CEUA/UFU 092/10.

\section{RESULTS}

The 25 rats were exposed to households expected to be infested with the jigger fleas twice or three times. In total, data of 67 exposures were collected. In eight cases (11.9\%), tungiasis lesions were found. The number of lesions per rat ranged between 1 and 18 (mean: 8.5).

The numbers of hatched eggs and efficacies of the tested insecticides are shown in Table 2. No larvae hatched after treatment with the organophosphate dichlorvos. The efficacies of the other products tested varied between $17 \%$ and $57 \%$. Dichlorvos showed significantly higher efficacy than the other insecticides tested $(\mathrm{p}<0.0001)$. On day three, $21 / 29(72 \%)$ larvae in the deltamethrin group showed spontaneous movement. No other larvae in the intervention groups showed vital signs. In the control group, all 35 hatched larvae were fully active.

\section{DISCUSSION}

This is the first systematic study on the efficacy of insecticides against immature stages of $T$. penetrans. The data show that at a concentration commonly used by Brazilian control programs, only the organophosphate dichlorvos had an acceptable ovicidal efficacy. As with the exception of deltamethrin, hatched larvae did not show vital signs for the other products, a residual larvicidal effect is possible.

The use of insecticides has been considered one of the means in an integrated approach to control tungiasis in affected regions [5]. In this context, environmental

Table 1. Details of Insecticides Tested Against Eggs of Tunga penetrans

\begin{tabular}{|c|c|c|c|}
\hline Product & Producer & Active Ingredient & Tested Concentration \\
\hline Deltametrina 25 ce & Fersol, Mairinque, SP, Brazil & 25g/L Deltamethrin (type II Pyrethroid) & $0.25 \mathrm{~g} / \mathrm{L}\left(5.5 \mathrm{mg} / \mathrm{m}^{2}\right)$ \\
\hline Bifentol $200 \mathrm{sc}$ & ChemoNE, Bezerros, PE, Brazil & 200g/L Bifenthrin (type I Pyrethroid) & $0.6 \mathrm{~g} / \mathrm{L}\left(13.2 \mathrm{mg} / \mathrm{m}^{2}\right)$ \\
\hline DDVP 1000 ce & Fersol, Mairinque, SP, Brazil & 825 g/L Dichlorvos & $4.125 \mathrm{~g} / \mathrm{L}\left(90.75 \mathrm{mg} / \mathrm{m}^{2}\right)$ \\
\hline Vectron $10 \mathrm{sc}$ & Iharabras SA, Sorocaba, SP,Brazil & $100 \mathrm{~g} / \mathrm{L}$ Etofenprox & $2 \mathrm{~g} / \mathrm{L}\left(44 \mathrm{mg} / \mathrm{m}^{2}\right)$ \\
\hline
\end{tabular}


Table 2. Efficacy of Four Insectides Tested Against Eggs of Tunga penetrans

\begin{tabular}{|c|c|c|c|c|c|}
\hline Insecticide & Number of Eggs & Number of Larvae (= Hatched Eggs) & Crude Hatch Rate & Corrected Hatch Rate & Efficacy (95\% Confidence Interval) \\
\hline \hline Dichlorvos & 40 & 0 & $0 \%$ & $0 \%$ & $100 \%(92.1-100)$ \\
\hline Etofenprox & 40 & 15 & $37.5 \%$ & $42.9 \%$ & $57.1 \%(29.3-75.1)$ \\
\hline Bifenthrin & 40 & 18 & $45.0 \%$ & $51.4 \%$ & $48.6 \%(30.0-67.2)$ \\
\hline Deltametrin & 40 & 29 & $72.5 \%$ & $82.9 \%$ & $17.1 \% 0-35.7$ \\
\hline Control & 40 & 35 & $87.5 \%$ & $100 \%$ & $0 \%(0-16.6)$ \\
\hline
\end{tabular}

insecticide spraying should be considered an emergency intervention and would need integration with other more sustainable measures. In fact, recent studies have shown that intermittent application of a plant-based repellent reduced morbidity significantly, but that transmission and subsequently morbidity increased rapidly after interruption of this intervention [20]. Control ideally should consist of individual therapeutic measures, and interventions concerning improved housing and environmental conditions, and veterinary measures to reduce animal reservoirs such as cats, dogs, pigs and rats $[4,21]$. As off-host life stages of $T$. penetrans can be found indoors and/or outdoors (which may vary from setting to setting), the use of an efficacious insecticide such as dichlorvos may be performed in addition to these control measures, directed to typical areas where early stages are expected [14, 22, 23].

One matter of concern is the mammalian toxicity of dichlorvos, an organophosphate that is absorbed through skin, gastrointestinal tract and the respiratory system. The insecticide is highly volatile with a vapor pressure of 0.012

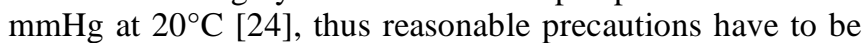
taken when used indoors. Organophosphates irreversibly inactivate the acetylcholine esterase. Overexposure may cause a variety of symptoms, according to the route of exposure. Whereas inhalation may cause ocular and respiratory symptoms, ingestion causes gastrointestinal discomfort. Dichlorvos may also lead to allergic contact dermatitis. In severe cases, paralysis of respiratory muscles can lead to death. Low-dose long-term effects are still discussed due to uncertainties in the study designs concerning dose and insecticide mixture [25].

Synthetic pyrethroids (deltamethrin, bifenthrin) are usually considered less toxic, but were less efficacious against eggs in our study. They block the voltage-dependent sodium channel resulting in a stable hyperexcitable state of tissues. Symptoms of acute pyrethroid intoxication include paraesthesia, nausea, headache, muscle fasciculation, dizziness, fatigue and convulsions. Only a few studies have been conducted concerning long-term toxicity of pyrethroids. The results support that there are limited effects in humans exposed to pyrethroids [26, 27].

Etofenprox is a non-ester synthetic pyrethroid with a similar mode of action. Yet its toxicity to humans and mammals is lower [28]. The main targets of acute intoxication are liver, kidney, thyroid and the hematopoietic system. The International Programme on Chemical Safety found no evidence for geno-toxicity [29]. The USEPA classified etofenprox as a possible human carcinogen. Mid- and long term data as to the chronic impact on humans still need to be evaluated.

As larvae hatched but did not show vital signs on day three in both, the Etofenprox and Bifenthrin group, a residual larvicidal effect of these compounds is possible.

In conclusion, we have shown that control of immature stages of $T$. penetrans with environmental insecticides is feasible in the context of an integrated control approach, at a concentration used currently by Brazilian authorities for the control of different insect species. Control measures against other endemic diseases using these insecticides may thus be integrated with tungiasis control in endemic settings. Further studies are needed to assess the efficacy of environmental insecticides of low toxicity under laboratory and field conditions.

\section{CONFLICT OF INTEREST}

The authors confirm that this article content has no conflict of interest.

\section{ACKNOWLEDGEMENTS}

We thank the Centro de Control de Zoonoses, Uberlândia and the Universidade Federal de Uberlândia, Uberlândia for support. The study was financed by a "Projeto Universal" grant from the Conselho Nacional de Desenvolvimento Científico e Tecnológico $(\mathrm{CNPq})$. $\mathrm{JH}$ is research fellow from CNPq.

\section{REFERENCES}

[1] Heukelbach J, de Oliveira FA, Hesse G, Feldmeier H. Tungiasis: a neglected health problem of poor communities. Trop Med Int Health 2001; 6: 267-72.

[2] Buckendahl J, Heukelbach J, Ariza L, Kehr JD, Seidenschwang M, Feldmeier H. Control of Tungiasis through Intermittent Application of a Plant-Based Repellent: An Intervention Study in a ResourcePoor Community in Brazil. PLoS Negl Trop Dis 2010; 4: e879.

[3] Heukelbach J. Invited Review: Tungiasis. Rev Inst Med Trop Sao Paulo 2005; 47: 307-13.

[4] Pilger D, Schwalfenberg S, Heukelbach J, et al. Investigations on the biology, epidemiology, pathology, and control of Tunga penetrans in Brazil: VII. The importance of animal reservoirs for human infestation. Parasitol Res 2008; 102: 875-80.

[5] Heukelbach J, Mencke N, Feldmeier H. Editorial: Cutaneous larva migrans and tungiasis: the challenge to control zoonotic ectoparasitoses associated with poverty. Trop Med Int Health 2002; 7: 907-10.

[6] Collins G, Mcleod T, Konfor NI, Lamnyam C, Ngarka LE, Njamnshi NL. Tungiasis: A neglected health problem in rural Cameroon. Int J Collab Res Intern Med Public Health 2009, 1: 210 .

[7] Ugbomoiko US, Ofoezie IE, Heukelbach J. Tungiasis: high prevalence, parasite load, and morbidity in a rural community in Lagos State, Nigeria. Int J Dermatol 2007; 46: 475-81. 
[8] Joseph JK, Bazile J, Mutter J, et al. Tungiasis in rural Haiti: a community-based response. Trans R Soc Trop Med Hyg 2006; 100: 970-4.

[9] de Carvalho RW, de Almeida AB, Barbosa-Silva SC, Amorim M, Ribeiro PC, Serra-Freire NM. The patterns of tungiasis in Araruama township, state of Rio de Janeiro, Brazil. Mem Inst Oswaldo Cruz 2003; 98: 31-6.

[10] Muehlen M, Heukelbach J, Wilcke T, Winter B, Mehlhorn $\mathrm{H}$, Feldmeier $\mathrm{H}$. Investigations on the biology, epidemiology, pathology and control of Tunga penetrans in Brazil. II. Prevalence, parasite load and topographic distribution of lesions in the population of a traditional fishing village. Parasitol Res 2003; 90(6):449-55.

[11] Feldmeier H, Heukelbach J, Eisele M, Sousa AQ, Barbosa LM, Carvalho CB. Bacterial superinfection in human tungiasis. Trop Med Int Health 2002; 7: 559-64.

[12] Wilcke T, Heukelbach J, César Sabóia Moura R, Regina Sansigolo Kerr-Pontes L, Feldmeier H. High prevalence of tungiasis in a poor neighbourhood in Fortaleza, Northeast Brazil. Acta Trop 2002; 83: 255-8.

[13] Ugbomoiko US, Ariza L, Heukelbach J. Pigs are the most important animal reservoir for Tunga penetrans (jigger flea) in rural Nigeria. Trop Doct 2008; 38: 226-7.

[14] Linardi, PM, Calheiros CML, Campelo-Junior EB, Duarte EM, Heukelbach J, Feldmeier H. Occurrence of the off-host life stages of Tunga penetrans (Siphonaptera) in various environments in Brazil. Ann Trop Med Parasitol 2010; 104: 337-45.

[15] Calheiros, CML. Aspectos biológicos e ecológicos de Tunga penetrans (L.,1758) (Siphonaptera: Tungidae) em áreas endêmicas brasileiras. Ciencas: Instituto de Ciêncas Biológicas, Universidade Federal de Minas, Gerais 2007.

[16] Nagy N, Abari E, D'Haese J, et al. Investigations on the life cycle and morphology of Tunga penetrans in Brazil. Parasitol Res 2007; 101: 233-42.

[17] Witt LH, Linardi PM, Meckes O, et al. Blood-feeding of Tunga penetrans males. Med Vet Entomol 2004; 18: 439-41.
[18] Eisele M, Heukelbach J, Van Marck E, et al. Investigations on the biology, epidemiology, pathology and control of Tunga penetrans in Brazil: I. Natural history of tungiasis in man. Parasitol Res 2003; 90: 87-99.

[19] Rosenheim JA, Hoy MA. Confidence Intervals for the Abbott's Formula Correction of Bioassay Data for Control Response. J Econ Entomol 1989; 82: 331-5.

[20] Feldmeier HJ, Kehr D, Heukelbach J. A plant-based repellent protects against Tunga penetrans infestation and sand flea disease. Acta Trop 2006; 99: 126-36.

[21] Heukelbach J. Revision on tungiasis: treatment options and prevention. Expert Rev Anti Infect Ther 2006; 4: 151-7.

[22] Witt L, Heukelbach J, Schwalfenberg S, Ribeiro RA, Harms G, Feldmeier H. Infestation of Wistar rats with Tunga penetrans in different microenvironments. Am J Trop Med Hyg 2007; 76: 6668.

[23] Ugbomoiko US, Ariza L, Ofoezie IE, Heukelbach J. Risk Factors for Tungiasis in Nigeria: Identification of Targets for Effective Intervention. PLoS Negl Trop Dis 2007; 1: e87.

[24] O'Neil MJ, Ed. The Merck Index: An Encyclopedia of Chemicals, Drugs, and Biologicals. Whitehouse Station, NJ: Merck \& Co Inc. 2001; pp. 541-2.

[25] Costa LG. Current issues in organophosphate toxicology. Clin Chim Acta 2006; 366: 1-13.

[26] Bradberry SM, Cage SA, Proudfoot AT, Vale JA. Poisoning due to Pyrethroids Toxicol Rev 2005; 24: 93-106.

[27] Vijverberg HP, van den Bercken J. Neurotoxicological effects an the mode of action of pyrethroid insecticides. Crit Rev Toxicol 1990; 21: 105-26.

[28] United States Environmental Protection Agency. Etofenprox: Human Health Risk Assessment for Proposed Section 3 Uses on Rice and as ULV Mosquito Adulticide.. Washington D.C.: USEPA, USA 2008.

[29] International Programme on Chemical Safety. Etofenprox Pesticide residues in food: 1993 evaluations Part II Toxicology. Geneva, Switzerland: IPCS, World Health Organisation 1993.

(C) Kiesewetter et al.; Licensee Bentham Open.

This is an open access article licensed under the terms of the Creative Commons Attribution Non-Commercial License (http://creativecommons.org/licenses/ by-nc/3.0/) which permits unrestricted, non-commercial use, distribution and reproduction in any medium, provided the work is properly cited. 